\title{
Synthesis and Characterization of Chinoform Sulfate
}

\author{
Kinzo Nagasawa and Hisae Yoshidome
}

School of Pharmaceutical Sciences, Kitasato University1)

(Received October 5, 1972)

Since its potential sterilizing activity was discovered by David in $1933,{ }^{2)}$ chinoform (5chloro-7-iodo-8-quinolinol) (I) has been widely used for the treatment of intestinal amebiasis. Recently, a possible relationship between the so-called SMON (Subacute myelo-optico neuropathy) disease and chinoform has been pointed out, ${ }^{3)}$ and examinations on the toxicity of chinoform are being extensively carried out by a number of investigators. In 1953, Haskins, et al. ${ }^{4)}$ reported the presence of sulfate and glucuronide of chinoform in the butanol extract obtained from the urine of chinoform-fed rabbits. More recently, Matsunaga and Tamura ${ }^{5)}$ reported an authentic synthesis of chinoform glucuronide (5-chloro-7-iodo-8-quinolyl- $\beta$-Dglucopyranosiduronic acid).

In this paper, we report the synthesis and properties of chinoform sulfate (5-chloro-7iodo-8-quinolyl sulfate) (II), and identification of II isolated from the urine of chinoform-fed rabbits.

\section{Result and Discussion}

Sulfation of chinoform was unsuccessful by the use of chlorosulfonic acid in pyridine which is one of the usual sulfation procedures, due to its remarkable side reaction. Triethylamine sulfur trioxide complex in dimethylformamide, which is known as an elegant reagent for the sulfation of carbohydrate compounds, ${ }^{6}{ }^{6}$ did not react with chinoform. After several trials, sulfation of chinoform was successfully achieved with chlorosulfonic acid in the presence of dimethylaniline in chloroform at room temperature, ${ }^{7)}$ and crystalline sodium salt of II was obtained in $87.4 \%$ yield.

Confirmation of the presence of one molar hydrolyzable sulfate and each proton on carbons in $2,3,4$, and 6 position of II proved that no change had occurred in the chinoform skeleton during this sulfation. The infrared (IR) spectrum on II reveals two strong absorptions at $1240\left(\nu \mathrm{SO}_{2}\right)$ and $1035(v \mathrm{SO}) \mathrm{cm}^{-1}$, characteristic of sulfate groups (Fig. 1-b). A comparison of ultraviolet (UV) spectra of II with that of chinoform shows that the introduction of a sulfate group into chinoform molecule resulted in lowering of the wave-length of its maximum absorption over all the $\mathrm{pH}$ range (Fig. 2-b). A similar effect due to sulfation has also been observed on 8-quinolinol.8) However, in contrast to 8-quinolinol, which acquires fluorescence by sulfation, II was nonfluorescent over all the $\mathrm{pH}$ range tested. ${ }^{9)}$ This contrary phenomenon is probably due to the effect of heavy atoms at $\mathrm{C} 5$ and $\mathrm{C} 7$ of quinoline skeleton. ${ }^{10}$ )

1) Location: 9-1 Shirokane 5 chome, Minato-ku, Tokyo, 108, Japan.

2) N.A. David, H.G. Johnstone, A.C. Reed, and C.D. Leake, J. Am. Med. Assoc., 100, 1658 (1933).

3) M. Yoshioka and Z. Tamura, Igaku No Ayumi, 74, 320 (1970).

4) W.T. Haskins and G.W. Luttermoser, J. Pharmacol. Exp. Therap., 109, 201 (1953).

5) I. Matsunaga and Z. Tamura, Chem. Pharm. Bull. (Tokyo), 19, 1056 (1971).

6) R.L. Whistler and W.W. Spencer, "Methods in carbohydrate chemistry," Vol. 4, by R.L. Whistler, Acad. Press, New York and London, 1964, p. 297.

7) When chinoform was reacted with the recommended reagent at higher temperatures, for example $50^{\circ}$, C-sulfonation of both chinoform and dimethylaniline occurred besides sulfation of chinoform.

8) R.W. Hay and J.A.G. Edmonds, Chem. Commun., 969, (1967).

9) K. Nagasawa and H. Yoshidome, unpublished work.

10) E.J. Bowen and F. Wokes, "Fluorescence of Solutions," Longmans, London, 1953. 
$\begin{array}{lllllllll}3600 & 2800 & 2000 & 1800 & 1600 & 1400 & 1200 & 1000 \quad 800\end{array}$
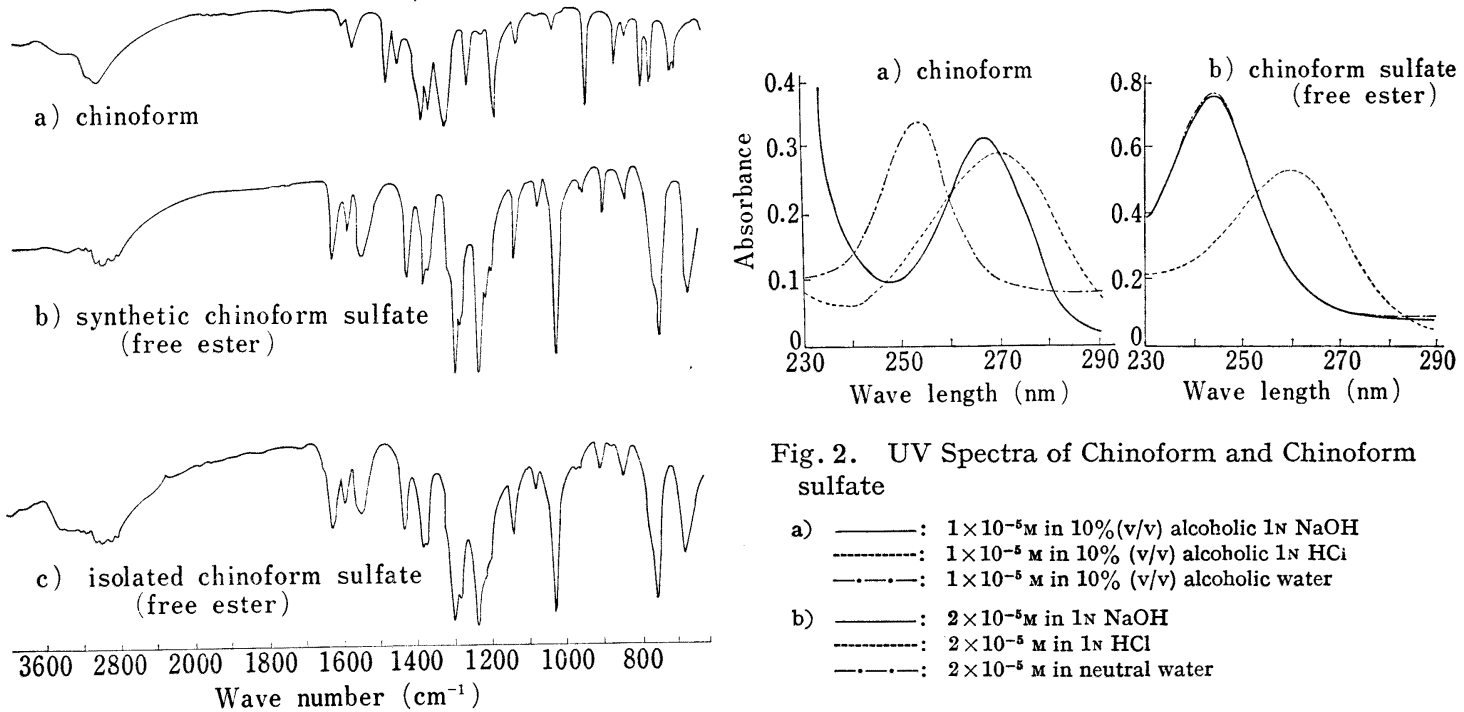

Fig. 2. UV Spectra of Chinoform and Chinoform sulfate

a) : $1 \times 10^{-5} \mathrm{M}$ in $10 \%(\mathrm{v} / \mathrm{v})$ alcoholic $1 \mathrm{~N} \mathrm{NaOH}$ -.... $1 \times 10^{-5} \mathrm{M}$ in $10 \%$ (v/v) alcoholic $1 \mathrm{~N} \mathrm{HC}$

b)

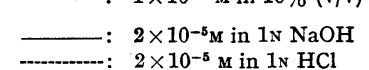

-....: $2 \times 10^{-5} \mathrm{M}$ in $1 \mathrm{~N} \mathrm{HCl}$

-.-.-: $2 \times 10^{-5} \mathrm{M}$ in neutral water

Fig. 1. IR Spectra of Chinoform and Synthetic and Isolated Chinoform Sulfates

It is known that $\mathrm{Cu}^{2+}$ enhanced not only the rate of hydrolysis of 8-quinolyl sulfate ${ }^{8)}$ but also its solvolytic reactivity.9) The effect of various metal ions on the rate of hydrolysis of II was examined. As shown in Table I, $\mathrm{Cu}^{2+}, \mathrm{Pd}^{2+}$, and $\mathrm{Hg}^{2+}$ markedly accelerated the rate of hydrolysis of chinoform sulfate in neutral medium at room temperature and the effect of $\mathrm{Cu}^{2+}$ was especially notable. In the case of $\mathrm{Ca}^{2+}, \mathrm{Zn}^{2+}, \mathrm{Al}^{3+}, \mathrm{Co}^{2+}, \mathrm{Ni}^{2+}, \mathrm{Mn}^{2+}$, and $\mathrm{Sr}^{2+}$, solution of chinoform sulfate remained unchanged in appearance and inorganic sulfate was also not detected even after $4 \mathrm{hr}$. In the presence of $\mathrm{Fe}^{3+}$, a trace of greenish precipitate was formed.

II gradually decomposed even in the absence of metal ions; the rate of its decomposition was 0,5 , and $50 \%$ after 7,24 , and $100 \mathrm{hr}$, respectively, in neutral aqueous solution at room temperature, but in $0.5 \mathrm{~N} \mathrm{NaOH}$ no detectable decomposition occurred. Quantitative ex-

TABLE I. Decomposition of Chinoform Sulfate (Na salt) in the presence of Metal Ions

\begin{tabular}{lccc}
\hline $\begin{array}{c}\text { Metal ion } \\
\text { added }\end{array}$ & $\begin{array}{c}\text { Decomposition } \\
\text { time(min) }\end{array}$ & $\begin{array}{c}\text { Degree of } \\
\text { decomposition }(\%)\end{array}$ & $\begin{array}{c}\text { Precipitate } \\
\text { formation }\end{array}$ \\
\hline $\mathrm{Cu}^{2+}$ & 0 & 63.5 & yellow precipitate \\
$\mathrm{Pb}^{2+b}$ & 5 & 100.0 & yellowish \\
& 10 & 38.5 & brown precipitate \\
$\mathrm{Hg}^{2+}$ & 30 & 79.9 & yellow precipitate \\
$\mathrm{Fe}^{3+}$ & 60 & 94.3 & a trace amount of \\
& 30 & 27.0 & greenish precipitate \\
$\mathrm{Cd}^{2+}, \mathrm{Zn}^{2+}, \mathrm{Al}^{3+}$, & 60 & 47.8 & no precipitation \\
$\mathrm{Mg}^{2+}, \mathrm{Co}^{2+}, \mathrm{Ni}^{2+}$, & 240 & & \\
$\mathrm{Mn}^{2+}, \mathrm{Sr}^{2+}$ & & 0 & \\
\hline
\end{tabular}

a) Metal chloride was used as a source of metal ion except $\mathrm{Hg}^{2+}$ which was used as its acetate.

b) $\mathrm{PbCl}_{2}$ was dissolved in $1 \mathrm{~N} \mathrm{HCl}$ and the acidic solution was used for this experiment without neutralization.

c) Formation of a trace amount of greenish precipitation was observed, but no inorganic sulfate was detected by Dodgson's turbidimetry. 
periment in acidic medium was impossible because of less solubility of II in $0.5 \mathrm{~N} \mathrm{HCl}$, but it might decompose moderately, for the spectrum of II converted to that of chinoform during measurement of UV spectra in $1 \mathrm{~N} \mathrm{HCl}$.

It was notable that II decomposed to chinoform and inorganic sulfate in anhydrous hexadetuerodimethyl sulfoxide used as a solvent during the measurement of its proton magnetic resonance (PMR) spectrum. The signal of $\mathrm{C} 6$ proton of II decreased as that of $\mathrm{C} 6$ proton of chinoform increased and finally the signal of the former disappeared and that of the proton of sulfuric acid appeared. In paper electrophoresis of the solution used for PMR measurement, spots of chinoform and inorganic sulfate were recognized but that of II could not be detected. As shown in Table II, the rate of decomposition of II in anhydrous dimethyl sulfoxide was markedly increased with an increase in temperature. A similar solvolytic desulfation in polar organic solvent has been observed in some steroid alcohol sulfates, ${ }^{11)}$ carbohydrate sulfate, ${ }^{12}$ ) and 8-quinolyl sulfate. ${ }^{9)}$

TABLE II. Decomposition of Chinoform Sulfate (Na salt) in Dimethyl Sulfoxide

\begin{tabular}{ccc}
\hline $\begin{array}{c}\text { Reaction condition } \\
\text { Temperature }\left(\mathrm{C}^{\circ}\right)\end{array}$ & Time $(\mathrm{min})$ & Degree of decomposition $(\%)$ \\
\hline 35 & 90 & 2.6 \\
& 150 & 6.3 \\
50 & 300 & 26.8 \\
& 30 & 10.0 \\
& 120 & 90.9 \\
& 180 & 100.8 \\
\hline
\end{tabular}

Conjugated chinoform fraction was obtained from urine of chinoform-fed rabbit by butanol extraction which was the same procedure used by Haskin, et al. ${ }^{4}$ The presence of a small spot corresponding to that of the synthetic chinoform sulfate was confirmed by both thin-layer chromatography (TLC) and paper electrophoresis. Substance corresponding to the spot was purified by repeated column chromatography over Avicel and subsequent recrystallization. As shown in Fig. 1, IR spectra of purified substance and of the synthetic sample were identical and, UV spectra at various $\mathrm{pHs}\left(\lambda_{\max }^{\mathrm{N} \mathrm{HCl}} 260 \mathrm{~nm}, \lambda_{\max }^{\mathrm{H} 2 \mathrm{O}}\left(\mathrm{pH}\right.\right.$ 7) $244 \mathrm{~nm}, \lambda_{\max }^{\mathrm{N}} \mathrm{NaOH}^{\mathrm{N}} 244$ $\mathrm{nm})$ agreed with these of the synthetic sample. Mobilities of purified sample on TLC and paper electrophoresis were also identical with that of the synthetic sample.

\section{Experimental}

Material—Purified chinoform ( $\mathrm{mp} 181^{\circ}$, sublimed at $170-175^{\circ}$ ) was obtained by recrystallization of commercially available chinoform. The organic solvents and reagents were all special reagent grade, and used without further purification except chlorosulfonic acid, N,N-dimethylaniline, and $\mathrm{CHCl}_{3}$ which were dried and distilled by the usual procedure.

Analytical Procedures_- The total and hydrolyzable sulfur content were determined by the oxygen combustion method and Dodgson's hydrolytic method followed by turbidimetry of inorganic sulfate formed, respectively. Paper electrophoresis was carried out on Toyo Roshi No. 51 paper with a buffer solution (pH 5.8) consisting of pyridine $(5 \mathrm{ml}), \mathrm{AcOH}(1 \mathrm{ml}), n-\mathrm{BuOH}(5 \mathrm{ml})$, and $\mathrm{H}_{2} \mathrm{O}(250 \mathrm{ml})$, at a potential of $23 \mathrm{~V} / \mathrm{cm}$, for $40 \mathrm{~min}$. TLC on cellulose powder, Avicel SF was carried out in $n$-BuOH saturated with $1 \mathrm{~N} \mathrm{NH}_{4} \mathrm{OH}$. The spots were detected under UV ray as dark spots on a light background. PMR spectra were measured at $35^{\circ}$ with a Varian T-60 NMR spectrometer operated at $60 \mathrm{MHz}$ in $10-12 \%$ solutions of samples in $\left(\mathrm{CD}_{3}\right)_{2^{-}}$ SO containing DSS (sodium 4,4-dimethyl-4-silapentane-1-sulfonate) as an internal standard. Chemical

11) S. Burstein and S. Liebermann, J. Am. Chem. Soc., 80, 5235 (1958).

12) A.I. Usov, K.S. Adamyants, L.T. Miroshnikova, A.A. Shaposhnikova, and N.K. Kochetkov, Carbohyd. Res., 18, 336 (1971). 
shifts were expressed in $\mathrm{ppm}$ on $\delta$ scale. IR spectra were measured in $\mathrm{KBr}$ disc with a JASCO Model IR-S and UV spectra were measured with Hitachi Recording Spectrophotometer EPS-3.

Sodium 5-Chloro-7-iodo-8-quinolylsulfate- $\mathrm{A} \mathrm{CHCl}_{3}$ solution $(10 \mathrm{ml})$ of chlorosulfonic acid (5.3 g, 0.05 mole) was added dropwise to a solution of $\mathrm{N}, \mathrm{N}$-dimethylaniline $(12.1 \mathrm{~g}, 0.1 \mathrm{~mole})$ in $\mathrm{CHCl}_{3}(250 \mathrm{ml})$ at $-2-0^{\circ}$. Recrystallized chinoform $(9.15 \mathrm{~g}, 0.03$ mole) was added to this solution and the reaction mixture was stirred for $5 \mathrm{hr}$ at room temperature. After the reaction, the precipitate was collected, washed with dry $\mathrm{CHCl}_{3}$, and dried in air. The dried precipitate was dissolved in warm $1 \mathrm{~N} \mathrm{NaOH}$ to form a homogeneous solution ( $\mathrm{pH} 7-8)$ which was allowed to stand in the cold to yield pale yellow needles $(10.69 \mathrm{~g}, 87.4 \%), \mathrm{mp}$ $190-191.5^{\circ}$ (decomp.); UV $\lambda \max \mathrm{nm}(\varepsilon) ; 244(39000)$ in $\mathrm{H}_{2} \mathrm{O}, 260(26000)$ in $1 \mathrm{~N} \mathrm{HCl,} 244(38000)$ in $1 \mathrm{~N} \mathrm{NaOH}$. Anal. Calcd. for $\mathrm{C}_{9} \mathrm{H}_{4} \mathrm{O}_{4} \mathrm{NSClINa}: \mathrm{C}, 26.52 ; \mathrm{H}, 0.99 ; \mathrm{N}, 3.44 ; \mathrm{S}, 7.87$. Found: $\mathrm{C}, 26.93 ; \mathrm{H}, 1.25 ; \mathrm{N}, 3.20$; $\mathrm{S}, 7.30$ (oxygen combustion method), 7.30 (hydrolytic method).

An aqueous solution of the sodium salt was added to an equivalent amount of $0.1 \mathrm{~N} \mathrm{HCl}$ and kept in the cold to separate thin-brownish needles of free chinoform sulfate. The crystals were collected on a glass filter and washed with a small amount of cold water, then dried over $\mathrm{P}_{2} \mathrm{O}_{5}$ in vacuo. The yield of the free ester, $\mathrm{mp} 191-193^{\circ}$ (decomp.), was almost quantitative.

Decomposition of Chinoform Sulfate in Aqueous Solution_-a) With Metal Ions: Sodium chinoform sulfate was dissolved in $\mathrm{H}_{2} \mathrm{O}$ to make a 10 mmole solution. A mixture of this solution $(0.5 \mathrm{ml})$ and $0.5 \mathrm{~m}$ metal chloride $(0.5 \mathrm{ml})$ was reacted at room temperature $\left(20-25^{\circ}\right)$. An aliquot $(0.1-0.2 \mathrm{ml})$ was removed from the reaction mixture at intervals and added to a small amount of Dowex 50 ( $\mathrm{H}^{+}$form) resin to remove metal ions. The supernatant of this reaction mixture was analyzed for inorganic sulfate.

b) Without Metal Ions: Sodium chinoform sulfate $(c a .60 \mathrm{mg})$ was dissolved in $5 \mathrm{ml}$ of either $\mathrm{H}_{2} \mathrm{O}$, $0.5 \mathrm{~N} \mathrm{NaOH}$, or $0.5 \mathrm{~N} \mathrm{HCl}$, and each of the solutions was allowed to stand at room temperature $\left(30^{\circ}\right)$. An aliquot $(0.1-0.2 \mathrm{ml})$ of this solution was removed at intervals and analyzed for inorganic sulfate.

Decomposition of Chinoform Sulfate in $\mathrm{Me}_{2} \mathrm{SO}$ - Sodium chinoform sulfate (ca. $60 \mathrm{mg}$ ) was dissolved in $5 \mathrm{ml}$ of anhyd. $\mathrm{Me}_{2} \mathrm{SO}$ to make a 0.15 mmole solution, and the solution was allowed to stand at $35^{\circ}$ or $50^{\circ}$. An aliquot of this solution was removed at intervals and analyzed for inorganic sulfate.

Isolation of Chinoform Sulfate from the Urine of Chinoform-fed Rabbit_-A suspension of chinoform $(4 \%(\mathrm{w} / \mathrm{v}), 12.5 \mathrm{ml})$ in $1 \%$ starch solution was administered once daily to a male rabbit (body weight, $2.5 \mathrm{~kg})$ orally, and the urine excreated was collected for 3 days. The urine $(425 \mathrm{ml}, \mathrm{pH}$ ca. 10) was extracted with five $200 \mathrm{ml}$ portions of $n-\mathrm{BuOH}$ and the combined extract was evaporated to dryness below $40^{\circ}$ at reduced pressure. Chromatographical examinations of this dried extract revealed the presence of a small spot whose $R f$ value coincided with that of synthetic chinoform sulfate, together with many large spots of unknown substances. The dried extract was dissolved in a small volume of $n-\mathrm{BuOH}$ saturated with $\mathrm{H}_{2} \mathrm{O}$ and chromatographed over a column $(2 \times 20 \mathrm{~cm})$ of Avicel using $n$ - $\mathrm{BuOH}$ saturated with $1 \mathrm{~N} \mathrm{NH}_{4} \mathrm{OH}$ as an eluting medium. The fractions containing the aimed material were combined and concentrated into a small volume at reduced pressure. This concentrate was rechromatographed under the same conditions to give a more purified material $(11 \mathrm{mg})$. This material was chromatographed again over a column $(1 \times 20 \mathrm{~cm})$ of Avicel using the same solvent to give a fairly purified material. This purified material was dissolved in $\mathrm{H}_{2} \mathrm{O}$ and the solution was acidified by the addition of a small amount of Dowex 50 ( $\mathrm{H}^{+}$form), then filtered. The clear solution which is slightly colored was kept in the cold to separate thin-brownish precipitate (ca. $2 \mathrm{mg}$ ). The chromatographic and spectrometric analyses were carried out with this purified material.

Acknowledgement The authors are greatly indebted to Dr. A. Ogamo, Miss K. Anryu, and Mr. H. Kashimura for their technical assistances. 